\title{
Effects of Isothermal Treatment on Microstructure and Scratch Test \\ Behavior of Plasma Sprayed Zirconia Coatings
}

\author{
Guilherme Veloso, Heleno Rocha Alves, José Roberto Tavares Branco* \\ REDEMAT (UFOP/CETEC/UEMG), Inst. Agronômico, Av. José Cândido da Silveira, 2000, \\ Belo Horizonte - MG, Brazil \\ www.cetec.br
}

Received: September 2, 2002; Revised: September 4, 2002

\begin{abstract}
The increase of the petroleum cost in the last decades revitalized the interest for lighter and more economic vehicles. Simultaneously, the demand for safe and unpolluted transports grows. The application of thermal barriers coatings (TBC) on combustion chamber and on flat surface of pistons reduces the thermal losses of the engines, resulting in higher temperatures in the combustion chamber. This fact contributes to the improvement of the thermal efficiency (performance) and for the reduction of incomplete combustion. Supported on these initial ideas, thermal barriers coatings constituted by $\mathrm{CaO}$ partially stabilized zirconia were produced and their microstructure examined.

This coating still presents some drawbacks associated with thermal stresses and permeability to oxidizing gases, which will, eventually, lead to failure of the TBC by spallation. The failure may, in general, be associated to one of three factors: oxide growth at the ceramic-metal interface, formed during thermal cycling; stress build-up due to thermal cycling; and metal-oxide interface segregation, mainly of S. However, it is also relevant to understand the behavior of TBC's under isothermal oxidation. Therefore, this paper investigates the effect of oxidation on the adherence of thermal sprayed coatings. The adherence was measured by linear scratching tests, widely used for thin coatings. Plasma sprayed calcia partially stabilized zirconia was used as TBC and Ni-5\% Al as bond coat, with $\mathrm{Al}$ substrates. Coated samples were submitted to heat treatments at $500{ }^{\circ} \mathrm{C}$, for $50 \mathrm{~h}$. The microstructures were examined by optical light microscopy, X-ray diffraction, profilometry and SEM.
\end{abstract}

Keywords: thermal barrier coatings, plasma spraying, microstructure, adhesion, scratching test

\section{Introduction}

The interest in the development of thermal barriers coatings (TBC) for applications in internal combustion engines has grown, motivated, among other factors, by environmental pressures. TBC's developed for propulsion turbines, to protect and improve durability of materials in the hot sections, are also used in the combustion chamber of reciprocating combustion engines to reduce heat loss (up to 40\%), to increase engine power and efficiency (up to 10\%) with significant fuel economy, and to decrease pollutant emis$\operatorname{sion}^{1}$. Additional benefits include the temperature reduction of the pistons and its rings and lubricant. The operation of these engines submits the coatings to thermal cycling, promoting, eventually, an adhesive flaw.

*e-mail: jbranco@cetec.br

Presented at the International Symposium on High Temperature Corrosion in Energy Related Systems, Angra dos Reis - RJ, September 2002.
Zirconia is commonly used as TBC due to its superior thermal insulating properties and high thermal shock resistance $^{2}$. It has three distinct crystallographic forms: monoclinic, tetragonal and cubic. On heating, the transformation from the monoclinic phase to the tetragonal one, around $1000{ }^{\circ} \mathrm{C}$, results in a volume increase of around $7 \%$, that can disrupt the coating ${ }^{3-6}$. To increase the TBC durability, the partially stabilized cubic phase, which is stable at higher temperatures up to the melting point, is employed. Using this expedient, the tetragonal to monoclinic transformation in the thermal spray process is avoided.

Plasma spraying is currently the most cost effective process for reciprocating engine parts. In this process, a feed stock 
powder is fed and heated in a plasma torch up to the melting. Particles of the molten liquid are projected towards a prepared substrate, where they are rapidly quenched, solidifying and producing a coating. There are variations of this technology, which is used in more than 34 industrial branches ${ }^{7}$.

Although the plasma torch reaches temperatures above $10^{4} \mathrm{~K}$, the residence time of the powder particles are of the order of milliseconds, and the low thermal conductivity of the zirconia prevents its overheating. This process generates porosity in the range $2 \%-10 \%$ in volume and micro cracks that, although benefitial to the thermal shock resistance and low thermal diffusivity, reduce the erosion resistance and allow penetration of corrosive gases ${ }^{8-10}$. In combustion engines the latter leads to thermally grown oxides - TGO.

TBC's exhibit multiple flaws mechanisms, some of them resulting in the ceramic layer separating from the substrate, which is referred to as spalling. During this process, cracks grow in the ceramic layer, close to the metal-ceramic interface or, when there is a bond-coat, close to the bond-coatceramic interface. This process starts with the oxidation of the metal substrate (or bond coat), introducing compressive stresses between the TGO and the metal. This stress, generated by the oxide growth process and by the difference in thermal expansion between the coating and the oxide layer, can reach 3 to $6 \mathrm{GPa}$. Eventually, this stress leads to buckling, crack growth and coalescence and, finally, spallation. Thermal cycling contributes to stress build up, due to the difference in thermal expansion coefficients of the coating components, Table 1.

The growth of the TGO layer is an important phenomenon in controlling the durability of the TBC system ${ }^{11-12}$.

Table 1. Average Thermal Expansion Coefficients, $\left(10^{6} \mathrm{~K}^{-1}\right)$.

\begin{tabular}{cccc}
\hline $\mathrm{ZrO}_{2}+\mathrm{CaO}$ & $\mathrm{TGO}\left(\mathrm{a} \mathrm{Al}_{2} \mathrm{O}_{3}\right)$ & $\mathrm{NiAl}$ & Aluminum \\
\hline $9-12$ & $8-9$ & 13 & $22-24$ \\
\hline
\end{tabular}

The metallic bond-coat act as an aluminum reservoir and is responsible for the formation of aluminum oxide. The preference for the aluminum oxide is related to its low growth rate and good adherence to its metal counterpart. The oxygen diffusion towards the substrate is inhibited by the TGO. The oxide growth consumes aluminum of the bond-coat, reducing the oxide layer capacity to be renewed when it is damaged. There is also a segregation at the metal/oxide interface.

The effect of oxidation has been widely investigated in thermal cycled systems. However, the effect of the isothermal oxide has not been widely looked at. Since adhesion is probably the most important aspect to indicate the service life of TBC's, another issue that deserves attention is the measurement of coating adherence. Pull-off testing has been the preferred option in industrial organizations, while interfacial indentation and bending tests have mostly been used in research groups. Each one has advantages and limitations ${ }^{9,13}$. Scratch testing has the advantage of being a very simple and inexpensive technique, since it does not require special sample preparation and a critical load can be determined in just one experiment. This test has been widely used to investigate thin films, $(<20 \mu \mathrm{m}$ thickness, $\mathrm{t})$. In this work, $\mathrm{ZrO} 2$ and $\mathrm{ZrO} 2 / \mathrm{NiAl}$ coatings, as sprayed and after heat treating at $500{ }^{\circ} \mathrm{C} / 50 \mathrm{~h}$ were subjected to scratch testing with constant normal load.

\section{Experimental Procedure}

The substrate consisted of samples of a rolled $\mathrm{Al}$ alloy, with dimensions $100 \times 25,4 \times 5 \mathrm{~mm}^{3}$. The coupons to be coated were prepared by rounding their edges and grit blasting, followed by manual degreasing with a solution of water and detergent. The average roughness was $R_{a}=(5,4 \pm$ $0,3) \mu \mathrm{m}$. The samples were divided in two groups: samples coated with zirconia with a bond coating - BC (duplex) and without it (simple). The zirconia TBC was deposited with a thickness of $300 \mu \mathrm{m}$ and the BC with a thickness of $150 \mu \mathrm{m}$. The deposition parameters were as indicated in Table 2, and composition as in Table 3. The heat treatment, realized in

Table 2. Deposition Parameters.

\begin{tabular}{lccccccc}
\hline Coat Material & Current (A) & Voltage (V) & $\begin{array}{c}\text { Primary } \\
\text { Gás }\left(\mathrm{Ar}_{2}\right)\end{array}$ & $\begin{array}{c}\text { Secondary } \\
\text { Gás }\left(\mathrm{H}_{2}\right)\end{array}$ & $\begin{array}{c}\text { Carrier } \\
\text { Gas }\left(\mathrm{Ar}_{2}\right)\end{array}$ & Feed Rate & Spray Distance (mm) \\
\hline $\mathrm{ZrO}_{2}-\mathrm{CaO}$ & 500 & 50 & 80 & 15 & 40 & 80 & 100 \\
$\mathrm{NiAl}$ & 500 & 50 & 80 & 15 & 40 & 100 & 180 \\
\hline
\end{tabular}

Table 3. Feed Stock Materials.

\begin{tabular}{ccc}
\hline Powders composition (wt. $\%)$ & Particle shape & Particle size range $(\mu \mathrm{m})$ \\
\hline $\mathrm{Ni}-4,5 \% \mathrm{Al}$ composite & Spheroid (clad) & $-88+45$ \\
$\mathrm{ZrO}_{2}-(3,1 \mathrm{wt} . \%) \mathrm{CaO}$ & Angular (Fused and crushed) & $-105+37$ \\
\hline
\end{tabular}


air, started at room temperature, reached $500{ }^{\circ} \mathrm{C}$ at $20{ }^{\circ} \mathrm{C} / \mathrm{min}$, with $50 \mathrm{~h}$ of holding time, followed by cooling at $2{ }^{\circ} \mathrm{C} / \mathrm{min}$ down to room temperature.

For the metallographic examination, transverse sections were cut, using $\mathrm{SiC}$ disk, mounted in epofix ${ }^{\circledR}$ with a cure time of $7 \mathrm{~h}$, and grinded and polished afterwards with $\mathrm{SiC}$ sand paper in the sequence 320, 600, 800 and 1500 \#, followed by $1 \mathrm{~mm}$ diamond paste. Some samples were etched with $\mathrm{HF}: \mathrm{HNO}_{3}: \mathrm{H}_{2} \mathrm{O}$ solution, with a $15: 15: 70$ proportion, at approximately $75^{\circ} \mathrm{C}$, during $10 \mathrm{~min}$, followed by cleaning, letting the samples sit for $3 \mathrm{~h}$ in water and subsequently in ethyl alcohol for $24 \mathrm{~h}$. The coatings were characterized before and after heat treatment by optical light microscopy - OM, perfilometry, X-ray diffraction - XRD and Scanning Electron Microscopy - SEM. The scratch testing was accomplished using constant load and Rockwell C indentator,

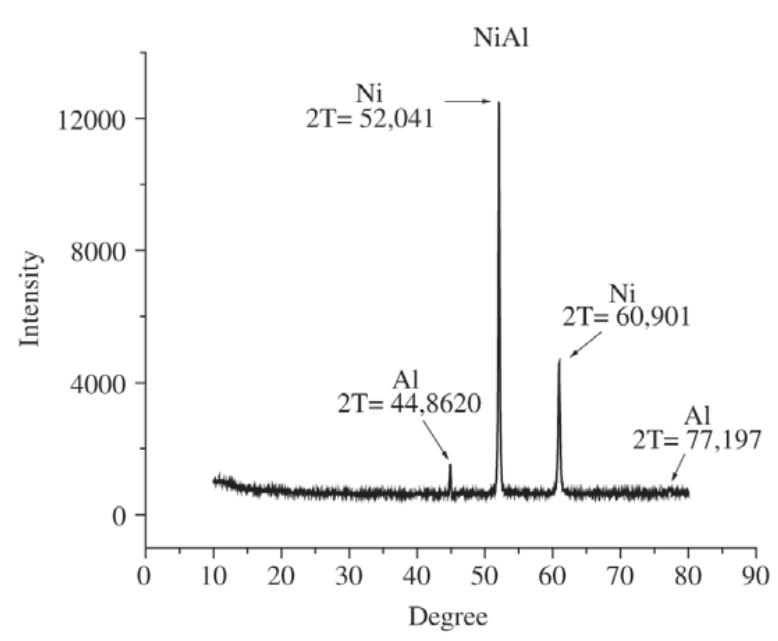

Figure 1. X - Ray Diffraction Spectra of feedstock NiAl.

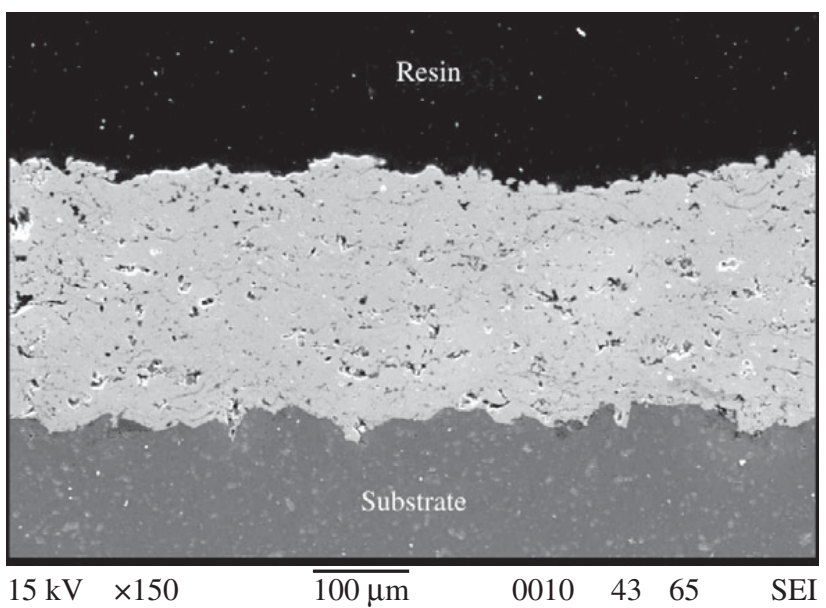

Figure 3. Cross section of $\mathrm{ZrO}_{2}$ coating, $\mathrm{ME}$ - SEI. starting with $5 \mathrm{~N}$ and increasing in $5 \mathrm{~N}$ steps until complete substrate exposition. The substrate hardness test employed a 2,5 mm tungsten carbide sphere, under a load of 31,25 N.

\section{Results and Discussion}

The Ni-Al feedstock is a composite powder, with small amounts of Aluminum phase, while the zirconia is mainly cubic with small amount of the monoclinic phase, Figs. 1 and 2. TBC coatings were ground for the XRD analysis.

Details of the structure and interface of the TBC can be seen in Fig. 3, showing that the zirconia structure is complex and heterogeneous. The as sprayed NiAl bond coatings present the characteristic lamellar structure of the plasma sprayed coatings, Fig 4 . The zirconium layer, seen from top in Figs 5 and 6, show that some zirconia particles

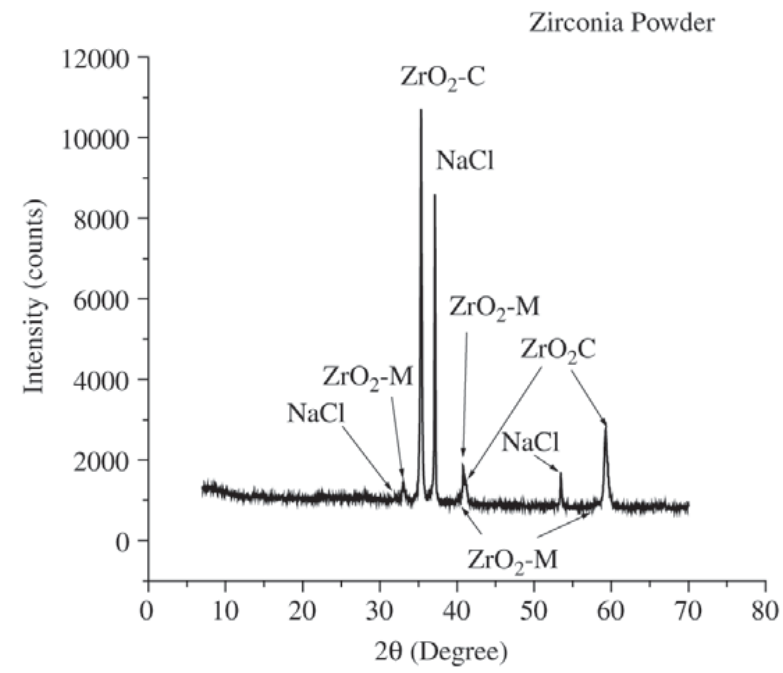

Figure 2. $\mathrm{X}$ - Ray Diffraction Spectra of feedstock $\mathrm{ZrO}_{2}$.

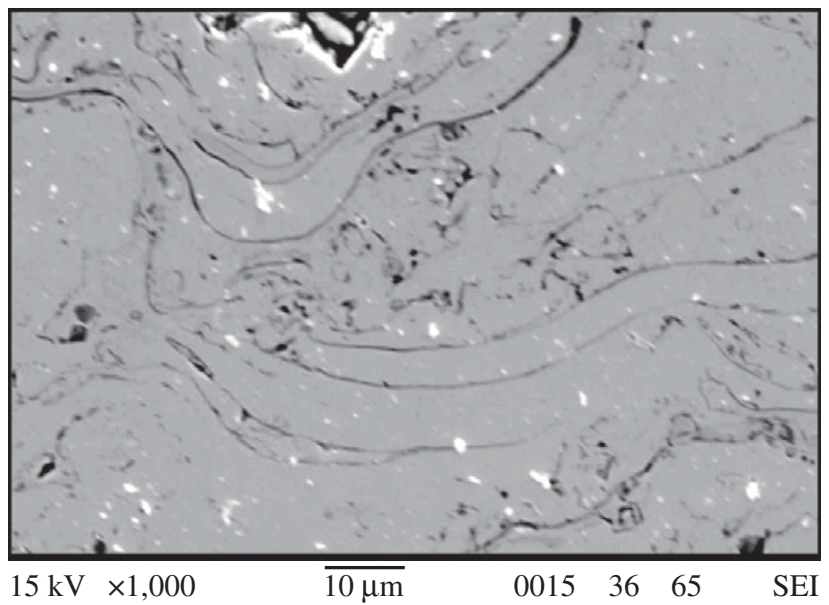

Figure 4. Cross-section $\mathrm{NiAl}$ intermediary layer. 

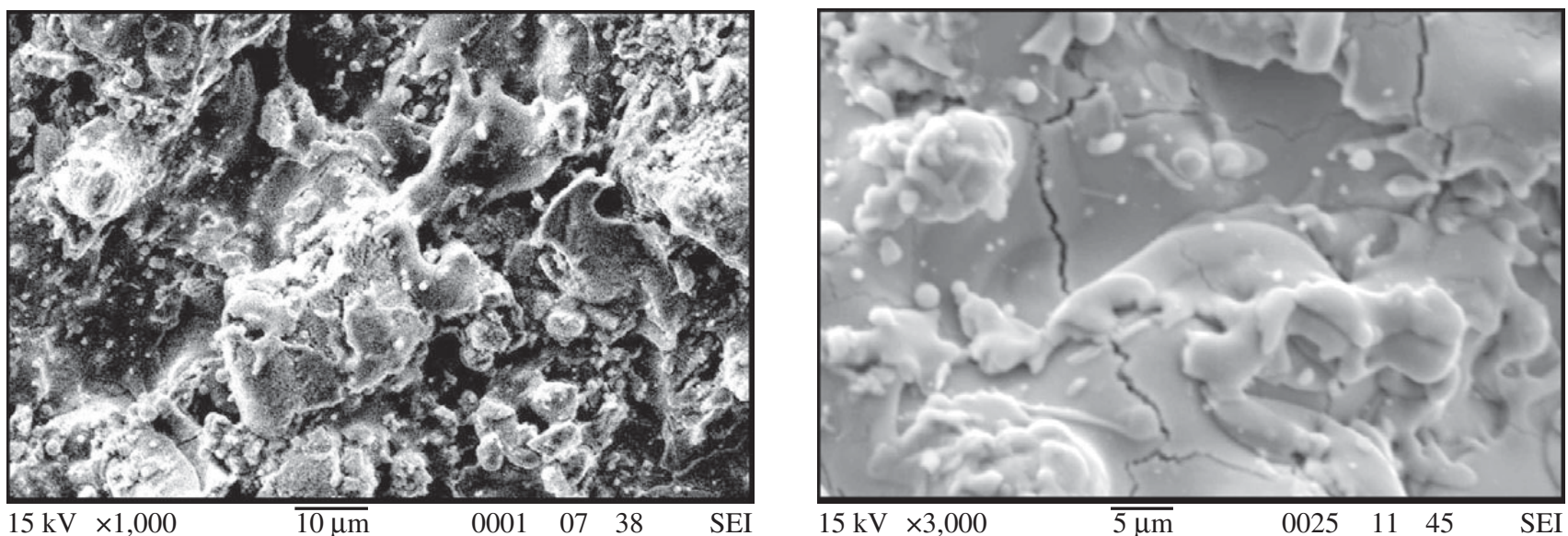

Figures 5 e 6. $\mathrm{ZrO}_{2}$ coating top view.
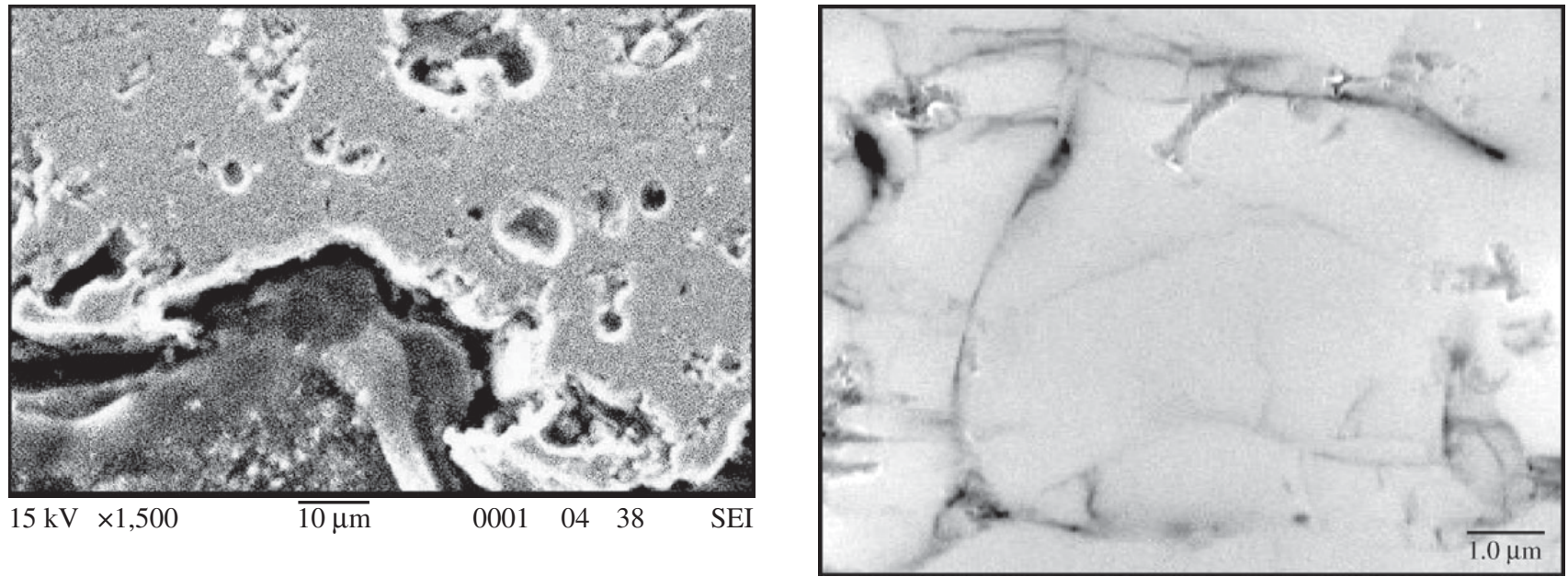

Figure 7. Spherical pores on Zirconia coating, MEV - SEI.

Figure 8. Micro cracks on Zirconia coating, MEV - SEI.
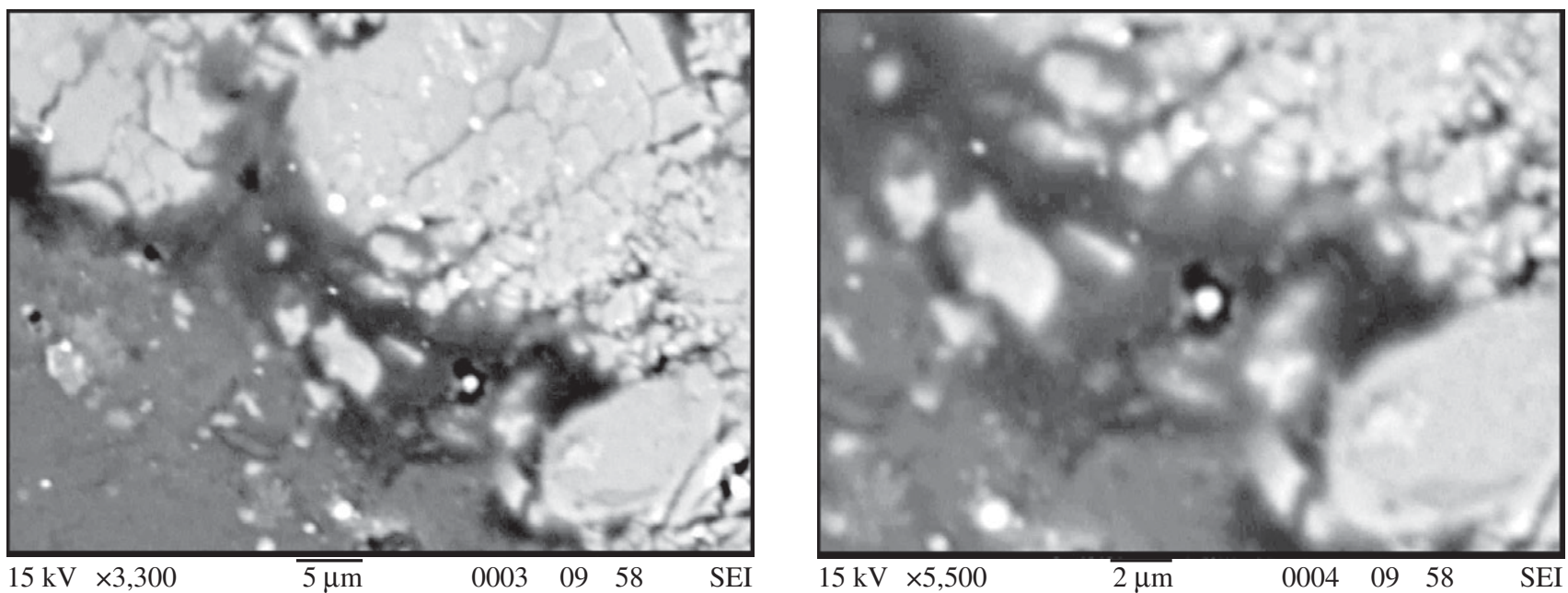

Figures 9 e10. TGO layer. 

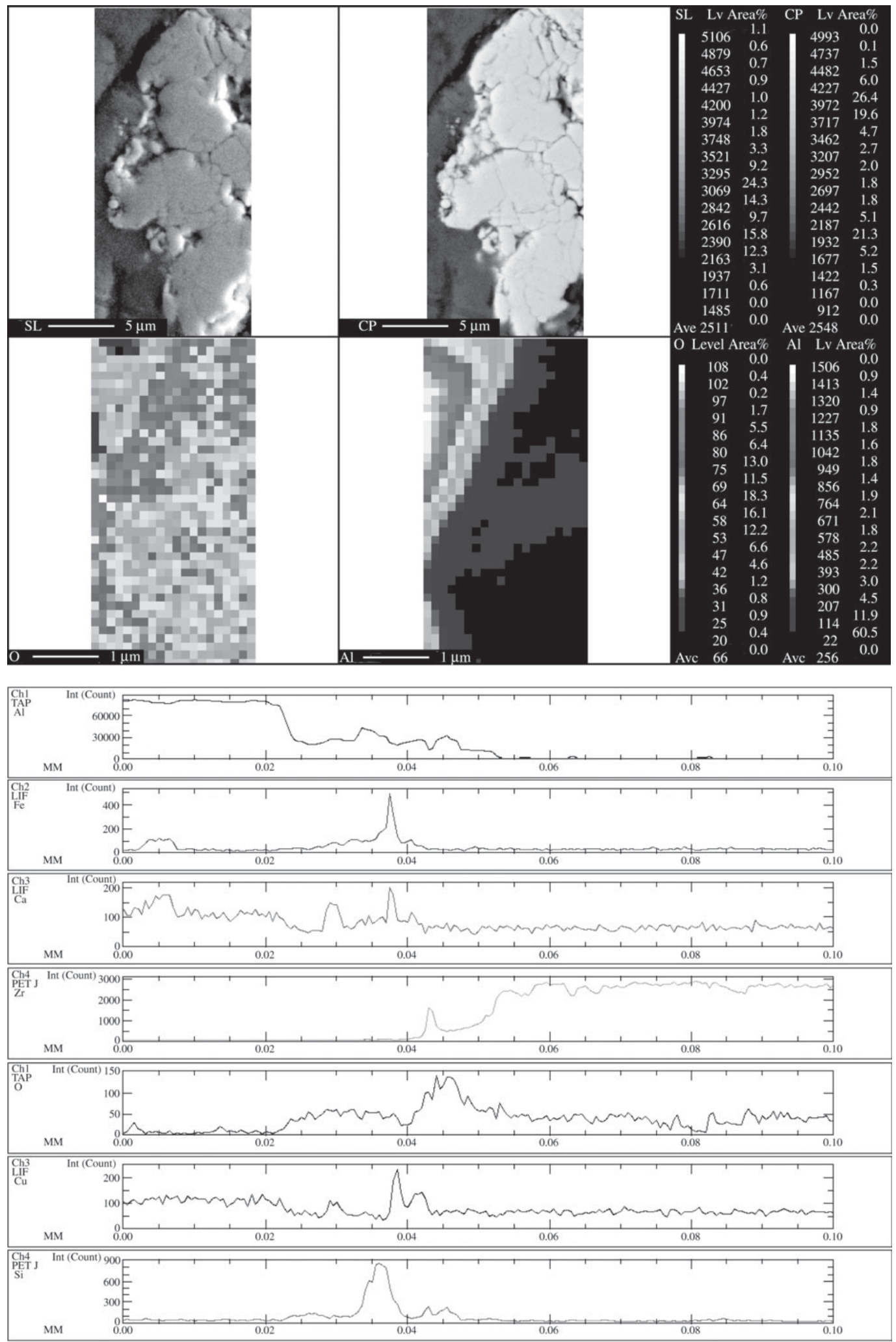

Figure 11. Electron micro-probe analysis of TGO showing a) SEI; b) BS; c)Oxygen and d)Aluminum maps. On the right side, line-scans across the substrate-zirconia interface, showing, from top to bottom, Aluminum, Iron, Calcium, Zirconium, Oxygen, Copper and Silicon. 
were melted and solidified before being incorporated into the coating while many show the peculiar lamellar shape, Fig. 6.

Figures 7 and 8 show the main features of the microstructure of the $\mathrm{CaO}$ partially stabilized zirconia coatings, which include voids with various shapes and dimensions, pores, lack of penetration of liquid splats, and cracks. The pores have rounded contours and exhibit a variety of dimensions, depending on their origin being due to dissolved gases in the liquid particles or gases that were produced from chemical reactions. The micro cracks, which are illustrated in Fig. 8, can be seen running perpendicular or parallel to the substrate as they form from thermal contraction during and after spraying, as well as from solidification and thermal shocks. After the heat treatment, the aluminum substrate softened from 40,4 to $36,8 \mathrm{HB} 2(5 / 31,25)$. A distinct region is noticeable at the substrate-TBC interface, Figs. 9 and 10. Composition maps of this region are shown in Fig. 11. The oxygen and aluminum images suggest formation of an alumina layer with thickness between 2 and $5 \mu \mathrm{m}$. XRD showed that plasma spraying prevented formation of the monoclinic phase, which was initially present in the zirconia feedstock. No effect of the heat treatment on the
TBC microstructure was detected.

The critical load for the scratch tests varied as shown in Table 4. A series of scratches with increasing loads were made, Fig. 12. Tensile and cohesive cracks were visible inside the scratches groves, in all coatings, as illustrated in Fig. 13. The transition from scratches just under critical load, left side, and after the critical load, right side can be seen in Fig 14. No spallation was observed during scratching of the heat treated $\mathrm{ZrO}_{2} / \mathrm{NiAl}$ sample, Fig 15.

The first mathematical analysis of the scratch testing, after Benjamin and Weaver, considered only the plastic deformation associated with indentation and scratching ${ }^{9}$. A more recent analysis by Bull and co-workers resulted in a model that relates the critical scratching load to adherence, through the work of adhesion, and is represented by Eq. 1. Three contributions to adhesive failure were identified: elastoplastic tension on penetration, tangential tension on friction and internal residual stress ${ }^{14}$.

$$
\mathrm{L}_{\mathrm{c}}=\frac{\pi \mathrm{d}^{2}{ }_{\mathrm{c}}}{8}\left[\frac{2 \mathrm{EW}}{\mathrm{t}}\right]^{1 / 2}
$$

Table 4. Critical Load for Zirconia Coatings Scratch Test

\begin{tabular}{cccc}
\hline & \multicolumn{3}{c}{ Critical Load for Zirconia Coatings Scratch Test } \\
$\mathrm{ZrO}_{2}$ as Sprayed & $\mathrm{ZrO}_{2} 500{ }^{\circ} \mathrm{C} / 50 \mathrm{~h}$ & $\mathrm{ZrO}_{2} / \mathrm{NiAl}$ as Sprayed & $\mathrm{ZrO}_{2} / \mathrm{NiAl}^{5} 50{ }^{\circ} \mathrm{C} / 50 \mathrm{~h}$ \\
\hline $60 \mathrm{~N}$ & $70 \mathrm{~N}$ & $145 \mathrm{~N}$ & $>200 \mathrm{~N}$ \\
\hline
\end{tabular}

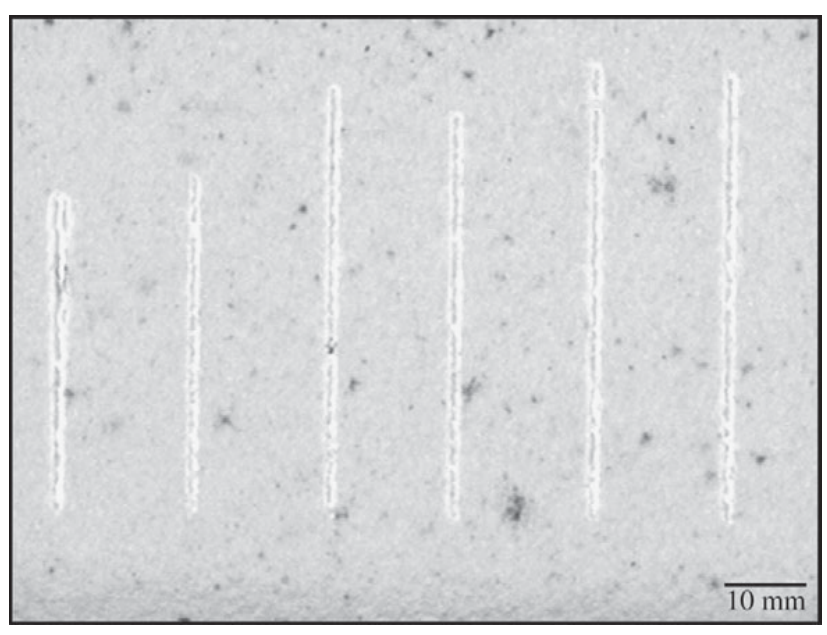

Figure 12. Scratch test with constant load.

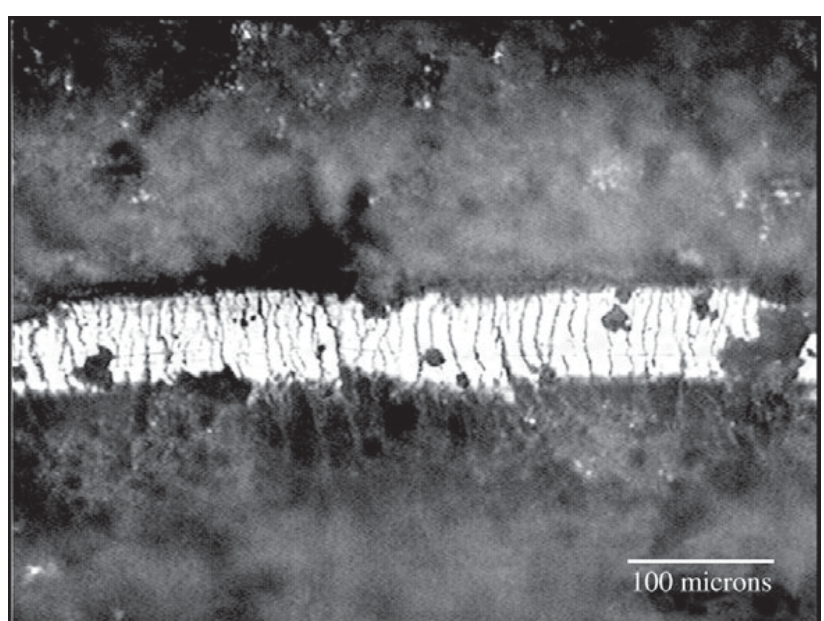

Figure 13. Tensile cracks (traction) $40 \mathrm{~N}$. 


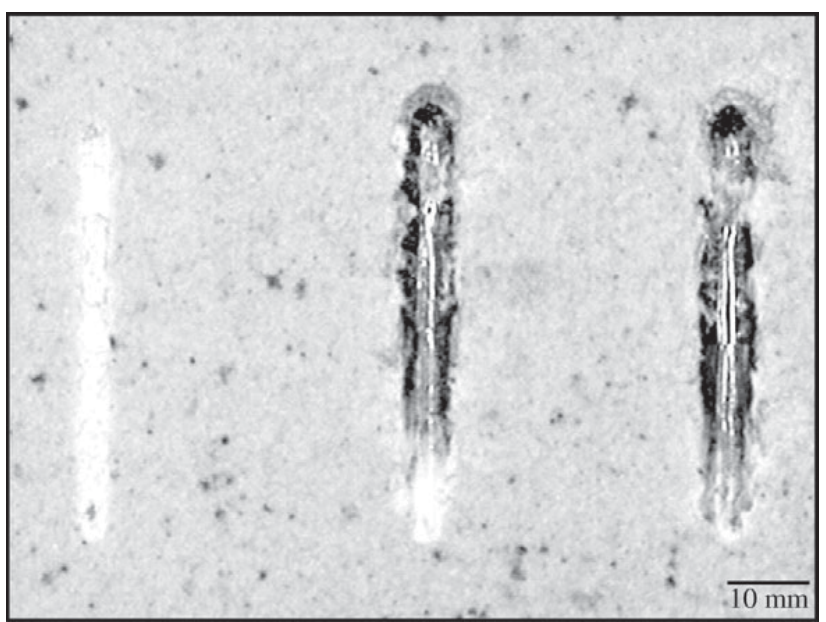

Figure 14. $\mathrm{ZrO}_{2} / \mathrm{NiAl}$ as Sprayed Scratch in critical load.

Where: $\mathrm{L}_{\mathrm{c}}=$ critical load

$\mathrm{d}_{\mathrm{c}}=$ scratch width

$\mathrm{E}=$ Young modulus

$\mathrm{W}=$ adhesive work

According to Eq. 1, the increase of the critical load is proportional to work of adhesion, considering the elastic modulus and the coating thickness constants. The improvement in adherence due to $\mathrm{Ni}-\mathrm{Al}$ bond coating, as previously reported, was confirmed. The heat treatment at $500{ }^{\circ} \mathrm{C}$ did not promote any detectable structural or phase changes and therefore it most likely did not affect the TBC elastic modulus. Therefore, the present results suggest that the heat treatment promoted an increase in the TBC adherence. This improvement may have been possible due to the continuous growth of the TGO, filling voids with the oxide and, therefore, increasing the mechanical interlocking with the TBC, as well as to the possibility that the soft Aluminum substrate could relax the stress. The lack of thermal cycling and thermal shock certainly decrease the stress load at the TGO/metal interface, and the combination of these factors most likely resulted in the improvement of adherence, as hereby reported.

\section{Conclusions}

- A plasma sprayed zirconia TBC was deposited on an Aluminum substrate, with a structure similar to what has been reported for low temperature substrates. Two groups of samples were prepared: the first had the zirconia deposited directly on the substrate, while the second had an intermediate Ni-Al bond coating.

- Adherence of the coatings was investigated using the scratch testing. This technique was able to promote coating

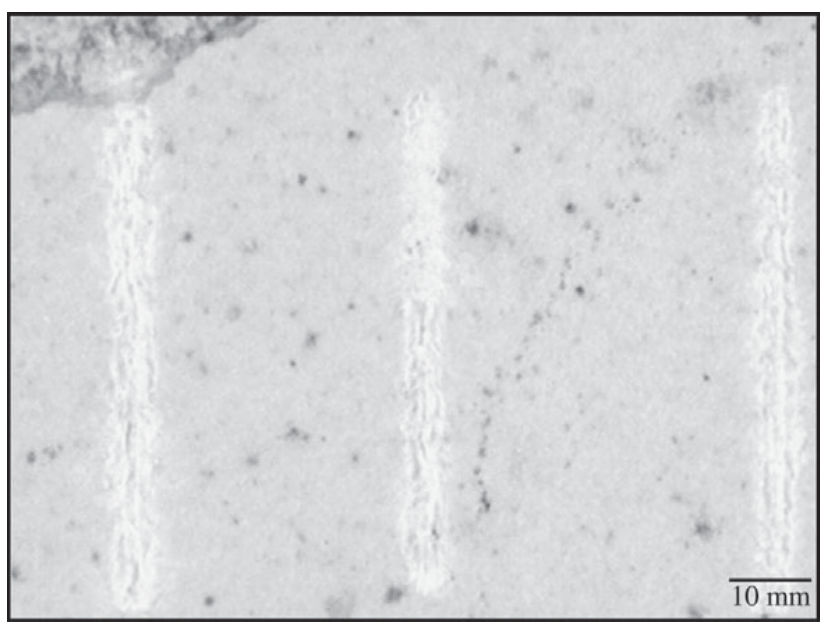

Figure 15. $\mathrm{ZrO}_{2} / \mathrm{NiAl} 500 \% / 50 \mathrm{~h}$.

adhesive failure at fairly well defined loads. The results allowed a comparison to be made of the effects of the presence of a bond coating and of an oxidation heat treatment.

- The use of a Ni-Al bond coating improved adherence. The heat treatment at $500{ }^{\circ} \mathrm{C}$, which created a TGO at the Aluminum-TBC interface, also improved adherence. The latter was rationalized by the formation of an adherent oxide layer that improves metal to TBC contact. The stress resulting from the mismatch between the substrate and the oxide is proposed to relax in the soft aluminum substrate.

\section{Acknowledgment}

The authors acknowledge the financial support from Fundação Gorceix and FAPEMIG; to MAGNESITA S.A.,SENAI - MG and to SINDIREPA - Sindicato da Indústria Reparadora de Veículos e Acessórios we acknowledge receiving samples and fruitful discussions. Thanks are also extended to Dr. Abá Persiano and UFMG, for electron micro-probe analysis, and to the metallographic laboratory from CETEC-MG.

\section{References}

1. Katayama, Y.; Kuroki H. Surface and Coatings Technology, Surface Treatment of Plasma-sprayed Ceramics Coatings by a Laser Beam, v. 34, p. 59-67,1988.

2. Pierz, P. M. “ Thermal barrier coating development for diesel engine aluminum pistons”, Surface and Coatings Technology, v. 61, p. 60-66, 1993.

3. Hobbs, M. K.; Reiter, H. "Residual Stresses in $\mathrm{ZrO}_{2}-8 \%$ $\mathrm{Y}_{2} \mathrm{O}_{3}$ Plasma Sprayed Thermal Barrier Coatings”, Advances in Coatings Technology - Conference Pro- 
ceedings, p. 285-290,setembro 1987.

4. Schütze, M. "An approach to a global model of the mechanical behaviour of oxide scales", Materials at High Temperatures, v. 12, p. 237-247, 1994.

5. Schütze, M. "Mechanical Properties of Oxide Scales", Oxidation of Metals, v. 44, p. 29-61, 1995.

6. Hoag, K.L.; Frisch, S.R.; Yonushonis, T.M. "Thermal Analysis of the Effect of Thick Thermal Barrier Coatings on Diesel Engine Performance", Proceedings of the $24^{\text {th }}$ Automotive Technology Development Contractor's Coordination Meeting, SAE, p. 90-97, 1986.

7. Steeper, T.J.; Riggs II, W.L. "A Taguchi Design of Experiment Study of Plasma Sprayed Alumina Coatings”, Procedings of the 1993 National Thermal Spray Conference, Anaheim, CA, June 1993.

8. Fauchais,P.; Vardelle,M.; Vardelle, A.; Bianchi,L. Ceramics International, v. 22, p. 295-303, 1996.

9. Bull, S.Jl; Rickerby, D.S. in D.S. Rickerby and A. Matthews, Advanced Surface Coating - A Handbook of Surface Engineering. P. 315-342 Published by Chapman and Fall - N.Y., 1991.

10. Smidt, F. A.; "Surface Modification", Advanced Materials and Process, v. 1, p. 61-62, 1990.

11. Evans, A. G.; Mumm, D. R.; Meier, G. H.; Hutchinson, J. W. Mechanisms controlling the durability of thermal barrier coatings - Progress in Materials Science 46, p. 505-553, 2001.

12. Evans, A. G.; He, M. Y.; Hutchinson, J. W. - Mechanicsbased scaling laws for the durability of thermal barrier coatings, Progress in Materials Science 46, 249-271, 2001.

13. Holmberg, K.; Matthews, A. Coating Tribology - Properties, techniques and applications in surface engineering. Elsevier, 1994.

14. Bull, S. J.; Rickerby, D. S.; Matthews, A.; Leyland, A.; Pace, A.R. The use of scratch adhesion testing for the determination of interfacial adhesion: The importance of frictional drag. Surf. Coat. Technol. 36, p. 503-517, 1988. 